(forthcoming in Res Philosophica; penultimate draft—please cite published version)

\title{
Descartes and the Possibility of Enlightened Freedom ${ }^{1,2}$
}

\author{
Daniel Fogal \\ Uppsala University
}

\section{Introduction}

Descartes's scattered remarks on the nature of human freedom are individually intriguing and collectively confusing. Several seemingly divergent patterns of thought are present in his writings, creating ample fodder for scholarly debate. Reactions range from allegations of incoherence to inconsistency to change over time. Although I don't think any of these charges stick, I won't be directly engaging with each controversy in the expansive literature. Instead, I'll outline an interpretation that promises to vindicate the coherence, consistency, and stability of Descartes's view - a view of considerable philosophical (and not just historical) interest. This is just what we should expect from someone who is not only highly intelligent and attentive to detail, but also prone to systematicity.

After some preliminary remarks (in $\mathbb{S I I}$ ), I set the stage for my preferred interpretation by canvassing Descartes's central commitments concerning human freedom and showing how they give rise to an important puzzle, one that is presented in a particularly precise and perspicuous way by what I call the "Anti-Enlightened Freedom Argument" (in \$III). I then briefly examine two potential solutions to the puzzle (in \$IV), both of which appeal to an ambiguity in Descartes's talk of ability. The first follows Campbell (1999) in interpreting Descartes along traditional compatibilist lines; the second follows Ragland (2016) in interpreting Descartes as a limited libertarian-i.e. as someone who accepts the reality of freedom but denies it is compatible with nearly all forms of determinism. I then provide an alternative interpretation of Descartes that shares similarities with those of Campbell and Ragland, but enjoys additional benefits besides (in $\mathbb{S V}$ ). I do so by appealing to the important but regularly overlooked distinction between possessing a power, exercising a power, and being in a position to exercise a power. The goal of this paper is thus to articulate a novel interpretation of Descartes that resolves an important tension at the heart of his view.

\section{Preliminary Remarks}

My main focus in what follows will be how-on Descartes's view-freedom relates to a certain form of determinism. Determinism is the thesis that, for any time $t$, the laws together

\footnotetext{
${ }^{1}$ Many thanks to Andrew Bailey, Don Garrett, John Maier, Lex Newman, Elliot Paul, Scott Ragland, and three anonymous referees for generous comments that led to substantial improvements. I owe a special debt of gratitude to Elliot Paul for getting me hooked on Descartes as a beginning graduate student, and to Scott Ragland for much encouragement since.

${ }^{2}$ References to Descartes are 'CSM' (1984-1985) and 'CSMK' (1991).
} 
with some proposition about the state of the universe at $t$ entail the state of the universe at every time later than $t .^{3}$ Although Descartes himself doesn't directly address the issue, he does discuss doctrines in the vicinity. In particular, Descartes's metaphysical framework raises the spectre of three distinct sorts of determinism:

physical determinism: for any time $t$, the complete physical state of the world at $t$ together with the laws of nature entails the subsequent physical state of the world.

intellectual determinism: for any time $t$ and subject $S$, the total intellectual state of $S$ at $t$ together with the psychological laws entails the subsequent state of S's will.

theological determinism: every event that occurs is preordained (and hence logically guaranteed) by a divine willing. ${ }^{4}$

Although Descartes's views vis-à-vis each are somewhat vexed and deserve extended treatment, the focus of this paper will be squarely on the determination of the will by the intellect. ${ }^{5}$ Some background concerning Descartes's metaphysics of mind is thus in order.

Like much of the contemporary debate surrounding human freedom, Descartes is concerned with the voluntary actions that we perform, and for which we are morally responsible. In the Meditations and elsewhere, however, Descartes is especially concerned with acts of the mind, or thinking substance. According to Descartes, the essence of mind is thought, understood as "everything that is within us in such a way that we are immediately aware of it" (CSM II, 113). There are two main kinds of thoughts:

All the modes of thinking that we experience within ourselves can be brought under two general headings: perception, or the operation of the intellect, and volition, or the operation of the will. Sensory perception, imagination and pure understanding are simply various modes of perception; desire, aversion, assertion, denial and doubt are various modes of willing. (CSM I, 204; italics added)

As this division of labor suggests, the locus of human freedom is the will—an intrinsic mental power-and its activity. The exercise of the will results in volitions, or acts of will. In-

\footnotetext{
${ }^{3}$ There are other things that might be meant by 'determinism'. For example, in their synoptic survey of seventeenth-century views of freedom, Sleigh, Chappell, and Della Rocca (1998) define 'determinism' as the thesis that "whatever happens in the world is brought about by causes other than itself" (1195). This is importantly different from the more contemporary characterization of determinism provided in the main text. The latter is closer to the thesis that whatever happens in the world is necessitated by causes other than itself, though the contemporary characterization says nothing specifically about causation.

${ }^{4}$ I've excluded reference to laws in the statement of theological determinism because I'm not sure what such laws would be-other than immutable divine willings, that is.

${ }^{5}$ For discussion of Descartes's view of causation-both physical and mental-see Schmaltz (2008), Chapters 2-4. For discussion of Descartes's view of the relationship between human freedom and divine providence, see Wee (2006, 2014), Cunning (2010), and Ragland (2005, 2016), among others.
} 
deed, Descartes identifies the will with the faculty of free choice: all acts of will are free, and all free acts are acts of will—acting freely is "the essence of will" (CSM II, 117). ${ }^{6}$

There are two broad kinds of volitions: choices-i.e. acts of pursuit or avoidance-and judgments - i.e. acts of affirmation, denial, and suspension. The fact that judgments are acts of will, and hence something over which we have (direct or indirect) voluntary control, is repeatedly made explicit (e.g. the appendix to the Fifth Replies), and the fact that we judge freely plays a key role in Descartes's larger epistemological project. ${ }^{7,8}$ Despite being fundamentally volitional in nature, judgments require the operation of the intellect as well. For judgments have content, and it is the intellect that provides the content. As Descartes puts it, whenever "we direct our will towards something, we always have some sort of understanding of some aspect of it" (CSM II, 259), and it is the intellect that enables us "to perceive the ideas which are subjects for possible judgments" (CSM II, 39). Intellectual perception is thus "a prerequisite of judgment"-any judgment concerning a proposition $p$ requires (at least some) awareness of $p$ (CSM I, 307). Analogous claims are true of choices. Call this the intellectual constraint on the will.

Descartes took judgments and choices to be constrained by the intellect in a second way as well. For not only must something be presented (however obscurely) in our mind in order to be a possible object of our judgment or choice, it must also have at least a semblance (however dim) of truth or goodness (e.g., CSM I, 392; CSM II, 291-92; CSMK, 56). The appearance of truth or goodness is what inclines the will towards the possible object of judgment or choice, though the will needn't always act on such inclinations. Call this the reasons constraint on the will. ${ }^{9}$

${ }^{6}$ Although Descartes takes the will to be a faculty or power of the mind, he denies that it occupies a discrete region of the mind; on the contrary, the "soul has within it no diversity of parts" (CSM I, 346) and "the term 'faculty' denotes nothing but a potentiality" (CSM I, 305).

${ }^{7}$ For example, in the Fourth Meditation Descartes confronts the problem of epistemic evil (or error) the problem, in brief, of how to reconcile the existence of an all-powerful, perfectly good God with the widespread existence of error, or false belief. Descartes's theodicy hinges on judgments being acts of will, and hence free, because it enables him to locate the source of and responsibility for error entirely in us - and, in particular, in the misuse of our will-rather than God. The similarities of this approach to the Augustinian solution to the problem of moral evil, or sin, are obvious. This interpretation of Descartes's theodicy is not without detractors, however. For a different take on Descartes's theodicy, see David Cunning (2007). (Thanks to an anonymous referee for the reference.)

${ }^{8}$ Descartes's theory of judgment notably departs from the prevailing Scholastic Aristotelian tradition, which located judgments in the intellect. For discussion, see Kenny (1972) and Greenberg (manuscript).

${ }^{9}$ This is why the so-called "method of doubt" is crucial for Descartes's purposes in the Meditations. For as Descartes makes clear in the appendix to the Fifth Set of Objections and Replies, one cannot withhold assent unless one has reason to do so-however slight and 'so to speak metaphysical' (CSM II, 270). In extricating the mind from its 'preconceived ideas', the entertaining of reasons for doubt is therefore more than a methodological aid-it's a methodological requirement (cf. Vitz 2010). If, on the contrary, suspension of judgment and disbelief were under the direct control of the will without any influence of the intellect, and so could be achieved merely by deciding to do so, the elaborate exercise of entertaining increasingly threatening skeptical scenarios would be unnecessary. 
In the next section I canvass some of Descartes's central commitments concerning freedom (\$III), and then introduce an important puzzle they engender (\$IV).

\section{Cartesian Commitments}

Although much of what Descartes wrote concerning the nature of freedom is subject to controversy, there is little doubt about his views concerning the reality of freedom: "That there is freedom in our will [is] so evident that it must be counted among the first and most common notions that are innate in us" (CSM I, 205-6). Thus:

1. Free Will Thesis: Humans act (choose, judge) freely.

As is standard, Descartes takes there to be an intimate connection between freedom and moral responsibility. For example, in the Principles he writes:

It is a supreme perfection in man that he acts voluntarily, that is, freely; this makes him in a special way the author of his actions and deserving of praise for what he does. (CSM I, 205; cf. CSMK, 277)

Acting freely is therefore sufficient for moral responsibility. It is also necessary, as evidenced by the following passage from the Passions:

I see only one thing in us which could give us good reason for esteeming ourselves, namely, the exercise of our free will and the control we have over our volitions. For we can reasonably be praised or blamed only for actions that depend upon this free will. (CSM I, 384; cf. CSMK, 325)

More formally, Descartes thinks that, for any subject $S$ and action (choice, judgment) $\varphi:^{10}$

2. Responsibility-Freedom Thesis: $S$ is morally responsible for $\varphi$-ing only if $S \varphi$-s freely.

But what is it to act freely, according to Descartes? Here controversy abounds. Descartes's most explicit and extended attempt to characterize the essence of the will, and hence freedom, appears in the Fourth Meditation. The immediate context concerns the similarity between our will and that of God's:

[I]t is above all in virtue of the will that I understand myself to bear in some way the image and likeness of God. For although God's will is incomparably greater than mine [in various respects]...nevertheless it does not seem any greater than mine when considered as will in the essential and strict sense. (CSM II, 40)

He then continues:

This is because the will simply consists in our ability to do or not do something (that is, to affirm or deny, to pursue or to avoid); or rather, it consists simply in the fact that when the intellect puts something forward for affirmation or denial or for pursuit or avoidance,

\footnotetext{
${ }^{10}$ See Jayasekera (2016) for discussion of the role responsibility plays in Descartes's theory of judgment.
} 
our inclinations are such that we do not feel we are determined by any external force. (CSM II, 40; italics added)

This passage is notable not only because it explicitly attempts to characterize the essence of the will, but also because it offers two seemingly different characterizations, side-by-side. Initially, the will is identified as a two-way power-i.e., "the ability to do or not to do something”. (Note that, like Descartes, I'll be using 'power' and 'ability' interchangeably.) This suggests, at a minimum, the following constraint on acting freely, for any action $\varphi:$ :

3. Two-Way Ability Thesis: $S \varphi$-s freely only if $S$ has the ability not to $\varphi \cdot{ }^{11,12}$

The Two-Way Ability Thesis receives support from a variety of texts. For example, in a note composed around 1645 (henceforth, 'the 1645 note'), Descartes insists that the will has the "positive faculty of determining [it] self to one or other of two contraries" with respect to all of its actions (CSMK, 245). ${ }^{13}$ Further support comes from the Principles:

[I]t is a supreme perfection in man that he acts voluntarily, that is, freely; this makes him in a special way the author of his actions and deserving of praise for what he does. We do not praise automatons for accurately producing all the movements they were designed to perform, because the production of these movements occurs necessarily. It is the designer who is praised for constructing such carefully-made devices; for in constructing them he acted not out of necessity but freely. By the same principle, when we embrace the truth, our doing so voluntarily is much more to our credit than would be the case if we could not do otherwise. (CSM I, 205; italics added)

The difference between humans and automatons-the reason we are morally responsible for our actions, but they are not-thus boils down to the fact that we act freely, and they don't (i.e. the Responsibility-Freedom Thesis). In explaining this point, however, Descartes contrasts our acting voluntarily, or freely, with that of acting out of necessity and then proceeds to seemingly equate our doing something "voluntarily" with our ability to "do otherwise".

This of course raises the question of what such an ability amounts to. Does it require, for example, that both $\varphi$-ing and not- $\varphi$-ing be genuinely open to you, holding fixed the state of the universe at or immediately prior to the moment of choice? Or does it merely require something weaker? This issue will loom large in what follows. Whatever Descartes happens to mean, however, it's somewhat odd that he immediately proceeds to offer another-and

11 The Two-Way Ability Thesis is oftentimes called the "Principle of Alternate Possibilities" (or "PAP", for short). This can be confusing, however, since Frankfurt's (1969) original principle of that name concerned moral responsibility rather than freedom. See Fischer (1999) for elaboration.

12 I'm suppressing time-indices for simplicity—and thereby bypassing certain controversies.

13 Though the note has traditionally been taken to be a letter intended for Mesland, the details concerning its exact date and intended recipient (if any) are subject to dispute. See Lennon (2013) for careful examination of the historical evidence. 
not obviously equivalent-characterization of freedom as self-determination, or the (felt) absence of external force. ${ }^{14}$ This, in turn, suggests:

4. Self-Determination Thesis: $S \varphi$-s freely only if $S$ is self-determining with respect to $\varphi$.

The statements flanking the 'or rather' (vel potius) thus introduce a prima facie ambiguity. Does acting freely require being able to choose between alternatives, or does it require acting in the absence of external force (i.e. of our own accord)—or both? There is scholarly disagreement on this point. As Schmaltz (2008) notes, it is common to view the two clauses as offering "two different kinds of freedom, with the first clause indicating a 'freedom of indifference' that requires [an] ability to do otherwise, and the second clause indicating a 'freedom of spontaneity' that does not require such an ability" (196). The 'or rather' is then read either as a retraction or else as an indication that the will can exhibit either kind of freedom. ${ }^{15}$ Ragland (2006c), however, convincingly argues against both readings, as does Schmaltz himself. Instead, it is "much more plausible that Descartes intended the second clause to further develop or clarify the first clause's claim that freedom requires alternative possibilities...'or rather' means 'in other (better) words'" (Ragland, 390). ${ }^{16}$

Though controversial, Descartes's acceptance of the Two-Way Ability Thesis together together with the Self-Determination Thesis is buttressed by the fact that apparent espousals of both appear throughout Descartes's writings. This lends significant support to the idea that Descartes views them as intimately related. Although for reasons of space I'm not able to defend these points at proper length, others have done so. (See especially Ragland 2006b and 2016, Chapters 3-6.) Readers who nonetheless remain wary of Descartes's commitment to the Two-Way Ability Thesis and/or the Self-Determination Thesis are encouraged to read this paper conditionally: if Descartes accepts both the Two-Way Ability and the Self-Determination Theses, how should we understand them?

Another element of Descartes's conception of human freedom emerges in the quotation from the Fourth Meditation with which we began. It continues as follows:

...In order to be free, there is no need for me to be inclined in both ways; on the contrary, the more I incline in one direction-either because I clearly understand that rea-

\footnotetext{
${ }^{14}$ Athough the second clause only requires that we feel undetermined, rather than actually be undetermined, there are good reasons to think the latter is also intended. As Ragland (2006b) notes,

[D]escartes is probably using the word 'feel' (sentiamus) here to reiterate his frequently stated opinion that we have an inner feeling or experience of freedom. Descartes suggests that this experience of freedom is clear and distinct, and hence (given the divine guarantee) veridical. So if in the experience of freedom we feel undetermined, we really are undetermined. (381)

Ragland (2006a) also points out that in the text immediately following the 'or rather' passage Descartes only talks about non-determination itself, not the feeling of such; this strongly suggests that it's the former that matters most. But not everyone agrees—see, for example, Cunning (2010, 2014b).

15 For the retraction readings, see Gilson (1913) and Beyssade (1994). The most prominent proponent of the either-or reading is Kenny (1972).

${ }^{16}$ Ragland provides a list of others who advance this sort of reading (p. 390, footnote 30 ).
} 
sons of truth and goodness point that way, or because of a divinely produced disposition of my inmost thoughts-the freer is my choice. Neither divine grace nor natural knowledge ever diminishes freedom; on the contrary, they increase and strengthen it. But the indifference I feel when there is no reason pushing me in one direction rather than another is the lowest grade of freedom; it is evidence not of any perfection of freedom, but rather of a defect in knowledge or a kind of negation... (CSM II, 40)

As this passage makes clear, Descartes thinks that human freedom is not something that requires one to be indifferent between alternatives. In the 1645 note Descartes clarifies that by 'indifference' he means "the state of the will when it is not impelled one way rather than another by any perception of truth or goodness" (CSMK, 245). Indifference is thus a matter of motivational ambivalence, and it admits of degrees: a person is "more indifferent the fewer reasons he knows which impel him to choose one side rather than another" (CSM II, 233). ${ }^{17}$ Accordingly, we arrive at the following:

5. No Indifference: $S$ 's being indifferent between alternatives is not a necessary condition of $S$ 's $\varphi$-ing freely. ${ }^{18}$

The final two Cartesian commitments concern the determination of the will by the intellect. As noted in $\mathbb{S I I}$, Descartes takes judgments and choices to require the operation of both the intellect and will, since the will is unable to form a judgment or choose unless the intellect first presents it with a proposition or potential course of action. There are thus mental or intellectual preconditions for any act of will; if these conditions together with the psychological laws are also sufficient, then intellectual determinism follows. But Descartes is averse to global intellectual determinism: although the contents of the intellect may sometimes determine the will to act in a particular way, they do not always do so. For God "has given me the freedom to assent or not assent in those cases where he did not endow my intellect with a clear and distinct perception" (CSM II, 42), and in such cases "[the will has] the freedom to direct itself, without the determination of the intellect, towards one side or the other" (CSM II, 260). Of course, for any form of determinism $D$, even if Descartes denies $D$ it doesn't follow that freedom is incompatible with $D$. The reality of freedom and the falsity

${ }^{17}$ In the 1645 note Descartes distinguishes two senses of 'indifference'. In the first sense, indifference is motivational ambivalence-i.e. as a lack of impulsion by any perception of truth or goodness. In the second sense, indifference is two-way power-i.e. "a positive faculty of determining oneself to one or other of two contraries" (CSMK, 245). Descartes takes indifference in the second sense to be necessary before, but not after, an act of will is elicited, while denying that indifference in first sense is a necessary condition of acting freely at any time (CSMK, 245).

${ }^{18}$ Although Descartes takes the No Indifference Thesis to characterize human freedom, it is not true of divine freedom: "If some reason for a thing's being good had existed prior to [God's] preordination, this would have determined God to prefer those things which was best to do" (CSM II, 294). This suggests that were God not indifferent prior to creation, God would have been determined in his actions (namely, to do that which was best) and hence not free. So at least prior to creation, God enjoyed a radical freedom of indifference. For more on human versus divine indifference, see Ragland (2006b, 382-283). 
of determinism do not imply the falsity of compatibilism. However, there's a good case to be made that Descartes is a compatibilist when it comes to freedom and a restricted form of intellectual determinism.

To see why, consider the concluding sentence of the main Fourth Meditation passage that has been our focus so far:

...For if I always saw clearly what was true and good, I should never have to deliberate about the right judgment or choice; in that case, although I should be wholly free, it would be impossible for me ever to be in a state of indifference. (CSM II, 40)

As this passage indicates, Descartes thinks that we would remain free even were we continuously (and, presumably, exclusively) presented with clear and distinct (CD-) perceptions, and hence never indifferent-i.e. never not impelled by a perception of truth or goodness. (Terminological note: since clarity and distinctness come in degrees, I'll reserve the use of 'CD-perception' to stand for perceptions that are completely clear and distinct, or at least clear and distinct enough to compel assent.) Indeed, the possibility of "perfectly enlightened" free agents-i.e. ones that continuously enjoy nothing but CD-perceptions-is explicitly countenanced a short while later:

God could easily have brought it about that without losing my freedom, and despite the limitations of my knowledge, I should nonetheless never make a mistake. He could, for example, have endowed my intellect with a clear and distinct perception of everything about which I was ever likely to deliberate; or he could simply have impressed it unforgettably on my memory that I should never make a judgment about anything which I did not clearly and distinctly understand. (CSM II, 42; cf. CSM I, 205)

Relevant here is the Cartesian doctrine of (what I'll call) CD-Determination-i.e. the thesis that CD-perception compels assent. ${ }^{19}$ More formally:

6. CD-Determination: Necessarily, for any subject $S$ and course of action/proposition $\varphi$, if $S$ CD-perceives $\varphi$, then $S$ chooses/judges that $\varphi .^{20}$

As Descartes notes, " $[\mathrm{m}] \mathrm{y}$ nature is such that so long as I perceive something very clearly and distinctly I cannot but believe that it is true" (CSM II, 48; cf. CSMK, 234). Likewise, the "will of a thinking thing is drawn voluntarily and freely (for this is the essence of will), but nonetheless inevitably, toward a clearly known good" (CSM II, 117). The will is thus determined to pursue/affirm whatever it CD-perceives as good/true, and likewise to avoid/reject whatever it CD-perceives as bad/false.

It's worth noting that Descartes doesn't just think it's possible for an agent to be perfectly enlightened; he thinks there are perfectly enlightened agents. In a 1644 letter to Mes-

\footnotetext{
${ }^{19}$ Cottingham (1993) takes this to be "the central doctrine of Descartes' Fourth Meditation" (64).

${ }^{20}$ Here again I suppress time indices for ease of exposition. Note that given the so-called "Truth Rule"i.e. necessarily, for any $S$ and any $p$, if $S$ CD-perceives that $p$, then $p$ is true-it follows that, necessarily, if $S$ CD-perceives $p$, then $S$ truly believes that $p$.
} 
land, for example, Descartes draws an analogy between the state of our will in cases of CDperception and that of "the blessed" in heaven, for whom "there is nothing in the intellect except light" (CSMK, 234). The salient difference is just that whereas for us such illumination is typically rare and fleeting, for the blessed it is a constant, persisting state. In both cases, however, the will is determined by the intellect and yet remains free. ${ }^{21}$ Thus:

7. Enlightened Freedom Thesis: Possibly, $S$ is perfectly (i.e. fully and continuously) enlightened, CD-Determination is true, and S nonetheless chooses/judges freely.

Since perfect enlightenment together with CD-Determination entails a form of intellectual determinism-in such circumstances the state of the will is always determined with law-like necessity by the state of the intellect-it follows that acting freely is compatible with at least one form of determinism. The plausibility of the Enlightened Freedom Thesis thus casts doubt on any interpretation of Descartes as a thoroughgoing libertarian-i.e. someone who accepts the reality of freedom and denies it's compatible with all forms of determinism. ${ }^{22}$

\section{A Puzzle: The Anti-Enlightened Freedom Argument}

So far, I have canvassed Descartes's central commitments concerning freedom. But there's a hitch-the Enlightened Freedom Thesis seems to conflict with Descartes's other commitments. Here's an argument, for any subject $S$ and action $\varphi:{ }^{23}$

\section{The Anti-Enlightened Freedom Argument}

1. Necessarily, if intellectual determinism is true of $S$, then $S$ does not have the ability to do otherwise than $S$ actually does. [plausible assumption]

2. Necessarily, $S \varphi$-s freely only if $S$ has the ability not to $\varphi$. [Two-Way Ability Thesis]

3. Necessarily, if $S$ is perfectly enlightened, then intellectual determinism is true of $S$. [def. of perfect enlightenment + CD-Determination + def. of intellectual determinism]

4. Necessarily, if intellectual determinism is true of $S$, then $S$ does not $\varphi$ freely. [from (1) and (2)]

5. Necessarily, if $S$ is perfectly enlightened, then $S$ does not $\varphi$ freely. [from (3) and (4)]

6. Therefore: Enlightened Freedom Thesis is false. [from (5) and Enlightened Freedom Thesis]

\footnotetext{
${ }^{21}$ For fuller defense and explication of the idea that the blessed in heaven are perfectly enlightened yet free, see Gilbert (2005). (Thanks to an anonymous referee for the reference.)

22 This includes recent interpretations advanced by Newman (2015) and Embry (2016), among others.

${ }^{23} \mathrm{I}$ 'm indebted to Andrew Bailey for this way of setting up the dialectic.
} 
The argument appears to be valid, and its conclusion is inconsistent with the possibility envisioned by Enlightened Freedom. In extricating Descartes from incoherence, the most obvious options are insisting that: [a] Descartes rejects the assumption that intellectual determinism is incompatible with the ability to do otherwise, and hence rejects (1), [b] Descartes rejects the Two-Way Ability Thesis, and hence rejects (2), [c] Descartes rejects the assumption that perfect enlightenment is a form of intellectual determinism, and hence rejects (3), [d] Descartes does not affirm the Enlightened Freedom Thesis, and hence accepts the conclusion (6), or [e] the argument equivocates on the use of 'ability to do otherwise' in (1) and (2), and hence is not in fact valid. ${ }^{24}$

Although each of the above options might be pursued with some plausibility, my focus will be on what I take to be the most promising way to defuse the Anti-Enlightened Freedom Argument-namely, by opting for [e], the claim that the argument is guilty of equivocation in its use of 'ability to do otherwise'. I'm not the first to make such a claim, however. Before I present my own defense of [e], then, I'll consider two others-the first by Campbell (1999) and the second by Ragland (2016).

\section{Alternative Interpretations: Campbell and Ragland}

A key motivation for the interpretation I favor is that it enables us to see how Descartes's various commitments might be reconciled with the Enlightened Freedom Thesis-i.e. the possibility of someone being perfectly (i.e. fully and continuously) enlightened, CD-Determination being true, and that person nonetheless judging and choosing freely. The strategy I wish to pursue involves distinguishes between different things that Descartes might mean when talking about the ability to do otherwise. A similar strategy has been pursued by others, though in different ways. In what follows I'll first explain the interpretation offered by Campbell ( $\mathbb{S V} . A$ ) before turning to Ragland ( $\mathbb{S V . B}$ ). Doing so will set the stage for the interpretation that I ultimately favor (\$VI).

\section{A. Traditional Compatibilism}

Campbell (1999) focuses much of his attention on the apparent tension between passages supporting the Two-Way Ability Thesis and those supporting CD-Determination. ${ }^{25}$ Recall:

CD-Determination: Necessarily, for any subject $S$ and course of action/proposition $\varphi$, if $S$ CD-perceives $\varphi$, then $S$ chooses/judges that $\varphi$.

Two-Way Ability Thesis: $S \varphi$-s freely only if $S$ has the ability not to $\varphi$.

Campbell interprets Descartes along traditional compatibilist lines. Traditional compatibilists deny that the ability relevant to freedom and responsibility is the "categorical" ability

\footnotetext{
${ }^{24}$ Of course, another option is to insist that Descartes's position is inconsistent. Although such a view may ultimately be forced upon us, I view the attribution of inconsistency or incoherence to Descartes as an option of last resort-i.e. only if there is no viable alternative explanation.

${ }^{25}$ Compatibilist interpretations of Descartes having been offered by others, including Chappell (1994).
} 
to do otherwise. Such an ability requires that it be possible to be in the exact same circumstances (actual past + laws) that one actually is in prior to acting, and yet nonetheless do otherwise than one in fact does. As it is sometimes put, there must be more than one possible way for you to "add" to the actual past. Thus:

Categorical TWA: $S$ is (categorically) able to do otherwise than $\varphi$ in circumstance $C$ only if, possibly, $C$ obtains and $S$ does something other than $\varphi .^{26}$

The categorical ability to do otherwise is clearly incompatible with CD-Determination.

In contrast, traditional compatibilists opt for "hypothetical" accounts of ability to do otherwise. These are views according to which one is able to do otherwise in a given circumstance $C$ (where $C$ is, say, the actual past up to the moment of choice together with the relevant laws) just in case some relevant counterfactual condition is satisfied. Thus:

Hypothetical TWA: $S$ is (hypothetically) able to do otherwise than $\varphi$ in $C$ if and only if $S$ would do otherwise were circumstances $C^{*}$ to obtain.

Different versions of Hypothetical TWA place different constraints on what $C^{*}$ amounts to, and hence vary in plausibility. Perhaps the most historically prominent version has it that one is able to do otherwise just in case one would do otherwise were one to want (or try or choose) to. This is supposed to capture the thought that freedom requires that there not be any external impediments to doing what one wants to do.

Why think Descartes advocated a hypothetical rather than a categorical account of the ability to do otherwise? The primary source of support comes from the following 'two senses' passage from the 1645 note:

...I do not deny that the will has this positive faculty [of determining oneself to one or other of two contraries]. Indeed, I think it has it not only with respect to those actions to which it is not pushed by any evident reasons on one side rather than on the other, but also with respect to all other actions; so that when a very evident reason moves us in one direction, although morally speaking we can hardly move in the contrary direction, absolutely speaking we can. For it is always open to us to hold back from pursuing a clearly known good, or from admitting a clearly perceived truth, provided we consider it a good thing to demonstrate the freedom of our will by so doing. (CSMK, 245; italics added)

This 'two senses' passage is notable for at least three reasons. First, Descartes distinguishes two senses in which one is able do otherwise: a 'moral' (or 'practical') sense and an 'absolute' (or 'metaphysical') sense. ${ }^{27}$ Second, Descartes claims that in the absolute (but not

\footnotetext{
${ }^{26}$ Note that Categorical TWA merely states a necessary condition for the relevant kind of ability.

${ }^{27}$ By different 'senses' I just mean different readings of 'can'-not that it has different meanings. According to linguistic orthodoxy, modal expressions like 'can', 'ought', 'must', and 'may' are context-sensitive, not ambiguous-see (e.g.) Kratzer (2012). Descartes himself, however, wasn't clear on the nature of the different readings that might be in play when he uses modal expressions-metaphysical, epistemic, moral, etc. For more on Descartes's metaphysics of modality and related puzzles, see Cunning (2014a).
} 
moral ${ }^{28}$ ) sense, we are always able to do otherwise than we in fact do-even in cases of CDperception. Third, the final clause (or "proviso") appears to provide an example of the way in which we are able to do otherwise-namely, by considering a reason to do otherwise.

Notice, however, that if being able to do otherwise in the absolute sense required the categorical ability to otherwise, then we would not be able to do otherwise than we in fact do in cases of CD-perception. For according to CD-Determination, it is impossible for someone to CD-perceive that $p$ without judging that $p$, and this is clearly incompatible with the categorical ability to otherwise. ${ }^{29}$ As Campbell points out, the same problem wouldn't arise if Descartes were to accept something along the lines of Hypothetical TWA instead. Interpreting the moral ability to do otherwise categorically and the absolute ability to do otherwise hypothetically might therefore seem promising.

Indeed, adopting such a view allows for a straightforward response to threat posed by the Anti-Enlightened Freedom Argument. For given the moral-absolute distinction, the first two premises will be ambiguous - do they concern the ability to do otherwise in the moral sense, or merely the absolute sense? Either way, the argument will turn out to be unsound. For suppose first that both premises-i.e. (1) and (2) - concern the ability to do otherwise in the moral sense. Then it turns out that while premise (1) is true-intellectual determinism is indeed incompatible with the moral (i.e. categorical) ability to do otherwisepremise (2) is false, since freedom only requires the absolute (i.e. hypothetical) ability to do otherwise. Alternatively, suppose it's the ability to do otherwise in the absolute sense that is at issue. Then the situation is reversed: premise (2) is true-freedom requires the absolute ability to do otherwise-but premise (1) is not-intellectual determinism is perfectly compatible with such. So although each of the first two premises are true under one possible reading, there is no reading under which both are true.

Despite its evident attractions, this interpretation is ultimately untenable. I take the following to be perhaps the most serious objection (cf. Ragland 2006a):

\section{Main Objection to Hypothetical TWA}

1. The hypothetical ability to do otherwise is compatible with global intellectual determinism.

2. Cartesian freedom is not compatible with global intellectual determinism.

3. Therefore, Cartesian freedom requires more than the hypothetical ability to do otherwise.

The first premise is fairly uncontroversial, and the second premise receives strong textual support from Descartes's exchange with Gassendi in the Fifth Set of Objections (see CSM II,

${ }^{28}$ Lennon (2013) demurs, insisting that "absolute possibility is the permissibility generated by the hyperbolic or metaphysical doubt in the service of unshakeable certainty" while "moral possibility concerns the practical generation of that doubt, [which] is very difficult, hardly possible" (240). On this reading of the two senses passage, that "the recovation of assent to a clear and distinct perception is possible in both senses-both morally (or practically) and absolutely (or metaphysically)" (241). For a response to Lennon, see Embry (2016), fn. 9.

${ }^{29}$ Or at least the direct categorical ability to do otherwise-I'll return to this point in Section VI.D. 
219ff), alluded to earlier. For in response to Gassendi's apparent espousal of global intellectual determinism and rejection of the will's indifference, Descartes denies that global intellectual determinism obtains. He insists not only that the will is free, but also that in order to be capable of guarding against error-given that God is not a deceiver-the will must have "the freedom to direct itself, without the determination of the intellect, towards one side or the other" in cases of unclear perception (CSM II, 260). The underlying structure of Descartes's reasoning appears to be this: if the will is always caused (and entailed) by the intellect-that is, if the determinism Gassendi proposes is true even in cases of unclear perception-then the will is not free, and God does not enjoy impunity. But the will is free, and at least in cases of unclear perception it is not determined by the intellect to will as it does. The problem is that this line of argument would be incongruous if Descartes were committed to a version of Hypothetical TWA, since it's not clear why the ability to do otherwise so understood would be threatened by global intellectual determinism. So it's doubtful that Descartes espoused a hypothetical account of the ability to do otherwise, understood along traditional lines. ${ }^{30}$

\section{B. Limited Libertarianism}

It's possible, however, that Descartes had a non-traditional hypothetical account of the "absolute" ability to do otherwise in mind. Indeed, a more promising interpretation emerges if we understand the relevant ability in the following schematic fashion:

Absolute TWA: $S$ is (absolutely) able to do otherwise than $\varphi$ in $C$ if and only if $S$ would be categorically able to do otherwise were certain circumstances $C^{*}$ to obtain.

Like Hypothetical TWA, Absolute TWA stands for a family of views, ones that differ depending on what, exactly, 'certain circumstances' amount to. The main difference between the traditional hypothetical account and this "nontraditional" one is that the traditional accounts involve a regular 'would'-counterfactual in the analysans-i.e. ' $S$ would do otherwise...'-while the nontraditional account involves an additional embedded modal claime.g. ' $S$ would be categorically able to do otherwise...'. Absolute TWA thus captures a kind of hypothetical categorical ability.

This is the interpretation of the 'two senses' passage favored by Ragland (2016). To see why, let's take another look:

...when a very evident reason moves us in one direction, although morally speaking we can hardly move in the contrary direction, absolutely speaking we can. For it is always open to us to hold back from pursuing a clearly known good, or from admitting a clearly perceived truth, provided we consider it a good thing to demonstrate the freedom of our will by so doing. (CSMK, 245)

\footnotetext{
${ }^{30}$ For an extensive catalogue of other prominent views concerning freedom and the ability to do otherwise espoused in the seventeenth century, see Sleigh, Chappell, and Della Rocca (1998). For a more contemporary—and influential—book-length discussion, see Fischer and Ravizza (1998).
} 
The final sentence is naturally read as an explanation ('for') of the sense in which 'absolutely speaking' we can move in the contrary direction, and it's the only clue Descartes gives us as to what it amounts to. And it's amenable to a gloss along the lines of Absolute TWA: in cases of clear (and presumably distinct ${ }^{31}$ ) perception, although morally-i.e. categoricallyspeaking we can't do otherwise than we actually do, absolutely speaking we can because it would be categorically open to us to hold back were we to have a reason to do so. On this reading, the proviso is taken to be an example of a relevant way in which things might be different, and in virtue of which we count as choosing or judging freely. That the proviso is an example rather than part of an analysis of what's required for such an ability is strongly suggested by the fact that it would be woefully inadequate otherwise-it would be implausibly narrow. When viewed merely as an example of the more general type of having at least some reason (however negligible), though, it's more plausible.

So there's reason to think Descartes advocated something like this:

Absolute TWA*: $S$ is (absolutely) able to do otherwise than $\varphi$ in $C$ if and only if $S$ would be categorically able to do otherwise were $S$ to have a reason not to $\varphi$.

Unlike Hypothetical TWA and Categorical TWA, Absolute TWA* analyzes one (sense of) ability to do otherwise-i.e. "absolute" ability—partly in terms of another-i.e. "categorical" ability. We arguably enjoy the former whenever we enjoy the latter, and even when we can't "morally" do otherwise we still count as being "absolutely" able to do otherwise so long as the relevant counterfactual in Absolute TWA* holds. And since (on Descartes's picture) it is satisfied with respect to all our choices/judgments, even when we're faced with nothing but CD-perception, it follows that we're absolutely able to do otherwise even when perfectly enlightened. On the assumption that freedom merely requires the absolute (rather than moral) ability to do otherwise, then, this interpretation is able to defuse the threat posed by the Anti-Enlightened Freedom Argument in much the same way Campbell's does - premise (1) would be true

\footnotetext{
${ }^{31}$ As an anonymous referee points out, the passage only mentions clearly perceived truths, rather than clearly and distinctly perceived truths. And as Descartes notes in the Principles, it's possible for an idea to be clear without being distinct (CSM I, 207-8). I nonetheless think the assumption of distinctness is plausible in contexts where the possibility of clear but indistinct ideas is neither remarked upon nor obviously relevant. This includes the 'two senses' passage as well as many others (including those written by commentators-see, for example, CSM II, 280-281). Take, for instance, the previously cited claim in the Fourth Meditation that "if I always saw clearly what was true and good, I should never have to deliberate [and] although I should be wholly free, it would be impossible for me ever to be in a state of indifference" (CSM II, 40; cf. CSM II, 104; CSM II, 291-292). This passage and others like it are standardly-and rightly, to my mind-cited in support of the Cartesian doctrine of that clear and distinct perception compels assent. But there's no mention of distinctness, only clarity. So-going back to the "two senses' passage-although Descartes may have meant we can always "hold back" from pursuing a clearly but not necessarily distinctly known good or from admitting a clearly but not necessarily distinctly perceived truth, I doubt it. Summarily put: in contexts where the possibility of clear yet indistinct ideas is irrelevant, it's plausible to interpret talk of clarity as convenient shorthand for clarity and distinctness.
} 
What's more, the ability specified by Absolute TWA* is incompatible with Gassendistyle global intellectual determinism. For even if $S$ were to have a reason not to $\varphi$ (assuming $S$ doesn't already), given global intellectual determinism it wouldn't follow that $S$ would be able to categorically do otherwise. On the contrary, $S$ wouldn't be able to do so, since $S$ would be determined to choose/judge whatever her intellect presented as best/most probable, regardless of any countervailing reasons. The incompatibility of Absolute TWA* with global intellectual determinism marks a significant improvement over the standard compatibilist interpretation advocated by the likes of Campbell. On the resulting view, all of Descartes's purported commitments are consistent and Descartes's reply to Gassendi makes sense. That's a substantial mark in favor of Ragland's interpretation.

But there are also problems. In particular, the counterfactual gloss of the 'two-senses' passage is admittedly somewhat forced-notice there are no 'had's, 'were's, or 'would's in it -and there's otherwise little textual support for Absolute TWA*. So it would be nice if we could avoid placing too much weight on such a thin reed. Indeed, the latter worry applies to any interpretations that treats the moral-absolute distinction as central to Descartes's theory of free will, including Campbell's and (to a lesser extent) Ragland's. ${ }^{32}$ For although any fully adequate interpretation will need to explain the moral-absolute distinction-the authenticity of the note is not in doubt-it turns out there are good reasons to discount its interpretative significance. Although space constraints prevent careful consideration here, Lennon (2013) argues persuasively that the significance traditionally assigned to it is misplaced. He summarizes the note's problematic status as follows:

The evidence is that Descartes struggled over the [1645 note], never sent it into the world, never commented on it elsewhere, and made no further use of it. For all we know, it is a record of views that he rejected. (247)

This fact should accordingly make us wary of any interpretation that treats the moral-absolute distinction as the cornerstone of Descartes's theory. Together with the forced nature of the counterfactual reading of the 'two senses' passage, we therefore have reason to the continue searching for a more satisfying interpretation of Descartes's conception of freedom.

\section{Restricted Incompatibilism}

Like the other interpretations considered so for, the interpretation I favor-which I'll call "Restricted Incompatibilism"-preserves the idea of two-way power or ability as being essential to the will. But it does so in a novel way. And that's by appealing to the independently motivated distinction between possessing a power, exercising a power, and being in a position to exercise a power. Roughly put, to exercise a power is to make use of it, while to be in a

\footnotetext{
32 Ragland takes the categorical vs. hypothetical-categorical distinction to be implicit in other passages besides 'two senses' one. To the extent that he's right, this helps blunt the worry. Indeed, Ragland could in principle divorce the categorical vs. hypothetical-categorical distinction from the moral vs. absolute distinction by denying that the former is operative in the 'two sense' passage, but nonetheless insisting that it's operative elsewhere. I'm not able to pursue this possibility at proper length, but as we'll see, doing so would bring our respective interpretations considerably closer together.
} 
position to exercise a power is to (a) possess a power and (b) for there to be no internal or external impediments to the exercise of that power (cf. Kenny 1975, 133). In order to possess a power or ability one needn't exercise it, nor even be in a position to exercise it. I possess the ability to jump, for example, even when I'm not exercising it (e.g. when I'm standing still) and even when I'm not in a position to do so (e.g. when I'm sleeping). We can thus distinguish a power's possession conditions-i.e., the conditions required to possess that power-from its opportunity conditions-i.e. the conditions that must be met in order to be able to exercise that power.

The distinction I'm concerned to draw is an intuitive one, and similar distinctions have been drawn by others. For example, van Inwagen (1983) writes the following:

Clearly there is a distinction to be made between a...general ability, on the one hand, and, on the other, the power to exercise it on a given occasion. This is true despite the fact that the same words might be used in both kinds of situation ('can speak French"; 'can move her left arm'; 'can play the flute'). (13)

In a similar vein, Mele (2003) writes:

Although I have not golfed for years, I am able to golf. I am not able to golf just now, however. I am in my office now, and it is too small to house a golf course. The ability to golf that I claimed I have may be termed a general practical ability. It is the kind of ability to A that we attribute to agents even though we know they have no opportunity to A at the time of attribution and we have no specific occasion for their A-ing in mind. The ability to golf that I denied I have is a specific practical ability, an ability an agent has at a time to A then or to A on some specified later occasion. (447)

It'll be useful to follow Mele in distinguishing between "general" and "specific" abilities. However, it's important to keep in mind that there's really only one kind of power or ability at issue, and that the general-specific distinction is intended to mark (something like) two modes of one and the same underlying power. For the sake of clarity, then, I'll regularly revert to the distinction between possessing a power and being in a position (and hence able) to exercise it.

Given the general-specific distinction, we face at least two questions: first, what's the relationship between general and specific abilities? And second, was Descartes aware of it, and if so to what degree? Regarding the first question, there are at least two options:

One...is that general ability is in some sense prior to specific ability: to have a specific ability is simply to have a general ability and to meet some further constraint, such as having an opportunity. Another proposal is that specific ability is in some sense prior to general ability: to have a general ability is simply to have a specific ability under a certain range of circumstances. (Maier 2014, Section 1.3) 
My interpretation is intended to be compatible with either route. So at least for present purposes, there's no need to take sides. ${ }^{33}$

Regarding the second question: I think Descartes was almost certainly aware of the distinction between general and specific abilities at some level, to some degree. After all, the distinction is an intuitive-and, upon reflection, quite obvious-one, and it's one that pervades much ordinary thought and talk about abilities. Given that Descartes regularly and unabashedly traffics in talk of powers and abilities, it's very likely that he would have employed the distinction in practice-just as we all do-even if he didn't explicitly remark upon it. But that doesn't prevents us (as theorists) from doing so-and once we do, we can turn our attention back to Descartes and carefully re-consider key texts to see where, and when, the distinction might have been implicitly operative. As we'll see, doing so will allow us to articulate with considerably greater clarity and distinctness an otherwise familiar picture of Descartes's conception of freedom, and to offer more straightforward interpretations of key texts than those currently on offer. ${ }^{34}$

\section{A. General vs. Specific Two-Way Ability}

My main proposal is simple: we can profitably understand Descartes's view as one according to which the possession of two-way power is in fact essential to free will, although such a power cannot be exercised unless an agent is in a state of indifference. It's therefore only in the general sense that the will always has two-way power-in the specific sense, the will's two-way power is limited to cases of indifference. That's the basic idea. I'll now spell it out more more fully, and (re-)consider key texts in light of it.

Let's begin with the Two-Way Ability Thesis-i.e. $S \varphi$-s freely if and only if $S$ has the ability not to $\varphi$. Given the general-specific distinction, it can be understood in at least one of two ways:

General Two-Way Ability (TWAG): $S \varphi$-s freely only if $S$ has the general ability not to $\varphi$.

Specific Two-Way Ability (TWAs): $S \varphi$-s freely only if $S$ has the specific ability not to $\varphi$.

On the view I'm proposing, Descartes endorsed TWA , but not TWA . It's of course a further question whether, when the opportunity conditions are met, the ability to do otherwise is categorical or hypothetical in nature. Recall:

Categorical TWA: $S$ is (categorically) able to do otherwise than $\varphi$ in circumstance $C$ only if, possibly, $C$ obtains and $S$ does something other than $\varphi$.

\footnotetext{
${ }^{33}$ For further discussion of the general-specific distinction, as well as its relevance to contemporary debates, see Franklin (2011a, 2015), Vihvelin (2013), and Maier (2015). For more fine-grained distinctions-ones that I'm ignoring in the interest of simplicity-see Clarke (2015).

34 There are important similarities (as well as differences) between the interpretation I offer and those of many others, including Kenny (1972), Ragland (2006a, 2016), and Schmaltz (2008, 192-208). Careful comparison with each is beyond the scope of this paper, though I discuss Kenny's view in footnote 45 and Ragland's (2016) view in footnotes 32, 38, 47, 50, and 52.
} 
Hypothetical TWA: $S$ is (hypothetically) able to do otherwise than $\varphi$ in $C$ if and only if $S$ would do otherwise were certain circumstances $C^{*}$ to obtain.

Like Ragland, I take Descartes's writings to strongly suggest the former, though I'm not able to defend this point at proper length (cf. Alanen 2002 and Wee 2006, 2014; for a less sanguine take, see Lennon 2013, 2015). Doing so would require, among other things, saying more about the nature of the possibility involved, as well as what exactly the relevant circumstances $C$ involve, and neither of these is an easy task. ${ }^{35}$ I'll nonetheless be taking it for granted that the possibility involved is broadly metaphysical in nature (and hence a logical possibility, assumings all metaphysical possibilities are logical possibilities). And since my focus is squarely on the threat of intellectual determinism, as opposed to physical or theological determinism, I'll be restricting $C$ to intellectual (pre)conditions. ${ }^{36}$ As a result, I won't be appealing to Categorical TWA in full generality. That's because, as noted above, the categorical ability to do otherwise requires that there be more than one possible way for you to "add" to the actual past state of the universe, given all the relevant laws-and the past presumably includes facts about the physical world as well as (at least potentially) God.

In order to make clear the limited scope of my claim, I'll therefore introduce a more restricted version of Categorical TWA (with subscript 'R' for 'Restricted'):

Categorical $\mathrm{R}_{\mathbf{R}}$ TWA: $\quad S$ is (categorically $\mathrm{y}_{\mathrm{R}}$ ) able to do otherwise than $\varphi$ in intellectual conditions $C$ only if, possibly, $C$ obtains and $S$ does something other than $\varphi$.

Categorical TWA entails Categorical ${ }_{R}$ TWA, but not vice versa. Accordingly, on the view I favor, Descartes at least embraced the following:

Cartesian TWAG: $S \varphi$-s freely only if $S$ has the general categorical ${ }_{R}$ ability not to $\varphi$.

We can now return to the Anti-Enlightened Freedom Argument. On the present interpretation-like those of Campbell and Ragland-the argument is guilty of equivocation. Recall the first two premises:

1. Necessarily, if intellectual determinism is true of $S$, then $S$ does not have the ability to do otherwise than $S$ actually does.

2. Necessarily, $S \varphi$-s freely only if $S$ has the ability not to $\varphi$.

Given the general-specific distinction, premises (1) and (2) are ambiguous-do they concern the categorical $\mathrm{R}_{\mathrm{R}}$ ability to do otherwise in the general sense, or merely the specific sense?

35 Descartes's modal metaphysics is a particularly messy affair. See, e.g., Nelson and Cunning (1998) and Cunning (2014a).

${ }^{36}$ If $C$ were taken to include facts about God's knowledge or will, for example, the threat of theological determinism would re-appear. Same goes for facts about (e.g.) the state of one's body and physical determinism. The extent to which intellectual determinism can be neatly divorced from either is nonetheless unclear. For discussion, see Schmaltz (2008), especially Chapters 3-5, and Wee (2006, 2014). (Thanks to an anonymous referee for raising this worry.) 
(Note that for ease of expression I'll regularly omit 'categorical $\mathrm{R}_{\mathrm{R}}$; the qualifier should be understood as implicit.) Either way, the argument will be unsound. For suppose first that both premises concern the ability to do otherwise in the specific sense. Then although premise (1) is true-intellectual determinism is indeed incompatible with the specific ability to do otherwise-premise (2) is false, since freedom only requires the general ability. Alternatively, suppose what's at issue is the ability to do otherwise in the general sense. Then the situation is reversed: premise (2) is true-freedom requires the general ability to do otherwise-but premise (1) is not-intellectual determinism (of a certain kind) is compatible with such. In sum: although each of the first two premises are true under one reading, there is no reading under which both are true. ${ }^{37}$

This potential resolution of the puzzle might itself seem puzzling, however. For the ability at issue is categorical in nature. One might wonder: how is the general ability to do otherwise compatible with a form of intellectual determinism, given that the specific ability is not? In response, note that, first of all, not only can one possess the ability to do something without ever actually exercising it, one can possess it without ever being in a position to exercise it - the opportunity conditions may never in fact arise. I may have the ability to kick a soccer ball, for example, without ever actually having done so (perhaps I abhor athletics), and without ever being in a position to do so (perhaps I've never been near a soccer ball). Likewise, a person might have the ability to see despite being in a medically-induced coma their entire life. In a similar way, one might have the ability to do otherwise without ever exercising it, and without ever being in a position to exercise it-the opportunity may have never arisen. Indeed, according to the interpretation on offer, this is precisely the situation perfectly enlightened agents (including "the blessed" in heaven) find themselves inthey possess two-way power, but they're not in a position to exercise it given the continuously enlightened state of their intellect. To use terminology familiar from recent debates concerning dispositions, their two-way power is "masked" in cases of CD-perception without being removed. As Clark (2009) notes:

[Masking conditions, or "masks",] prevent dispositions from manifesting without removing the dispositions. A poison's power to kill when ingested can be masked by an ingested antidote (Bird 1998, p. 228). A glass's fragility can be masked by internal packing that prevents breakage even if the glass is struck (Johnston 1992, p. 233).

Something similar applies to powers and abilities, which (I'm assuming) do not reduce to mere dispositions. (For discussion, see Maier 2014, Sections 1.1-1.2.) CD-perception can

\footnotetext{
${ }^{37}$ Notice that the structure-though not the substance-of this response is the same as the one available to Campbell, as well as Ragland. It's also worth noting that the proposed response to the Anti-Enlightened Freedom Argument is akin to how the "new dispositionalists" respond to Frankfurt-style cases. (Thanks to John Maier (p.c.) for this point.) In brief, the new dispositionalists think that agents in Frankfurt-style cases lack the specific ability to do otherwise but have the general ability to do otherwise, and that moral responsibility (as well as acting freely) only requires the latter. For critical discussion, see Clarke (2009), Franklin (2011b), and Maier (2014), section 5.2.
} 
thus be thought of as a masking condition-it prevents the manifestation of agents' twoway power without removing it.

Although the worry about the compatibility of the possession of (categorical ${ }_{R}$ ) twoway power and intellectual determinism may persist, it helps to keep in mind that the possession of such a power is not compatible with all forms of intellectual determinism. In particular, on Descartes's view, although the possession of such a power is compatible with a particular (or "local") form of intellectual determinism-namely, the one that holds of perfectly enlightened agents, given CD-Determination and the nature of the mind-it's not compatible with Gassendi-style global intellectual determinism. For suppose an enlightened agent were to have a reason to $\varphi$ as well as a reason not to $\varphi$. Then they would no longer be fully enlightened. Instead, they'd be in a state of indifference-i.e. not compelled by CDperception-and hence be able to exercise their two-way power. This is contrary to what would obtain if global intellectual determinism were true. For given global intellectual determinism, indifferent agents would never be able to exercise (categorical ${ }_{R}$ ) two-way power. Instead, they would be determined to choose or judge whatever their intellect presented as best or most probable, regardless of the presence of countervailing reasons.

The ability specified by Cartesian $\mathrm{TWA}_{\mathrm{G}}$ is thus akin to the ability specified by Absolute TWA*, which (as we saw above) is also incompatible with global intellectual determinism. The main difference is that whereas Absolute TWA* is an account of the ability to do otherwise in the "absolute" sense, and is formulated using a counterfactual conditional, Cartesian TWA $_{G}$ is neither. The latter is an improvement on both counts, given the problematic status and interpretation of the 'two senses' passage together with the fact that there are well-known problems plaguing counterfactual analyses in general. ${ }^{38}$

38 One might wonder: if I'm not in a position to exercise some power, what does it mean to say that I still possess the power? The following seems plausible: I possess the power just in case were the masking conditions absent, I would be in a position to exercise the power. But then it looks like general categorical two-way ability and Ragland's hypothetical-categorical two-way ability amount to the same thing. (Thanks to Ragland (p.c.) for raising this worry.) In response, I concede that if possessing a power is to be analysed in counterfactual terms, then the distinction at the heart of my interpretation collapses into (a restricted version of) Ragland's. The difference between our overall interpretations would then mainly boil down to a difference in emphasis as well as a difference in the interpretation of several key passages, including the 'two senses' , 'or rather', and 'automatons' passages. In particular, whereas I emphasize the priority in Descartes's system of the positive power of self-determination and take it to explain two-way power, Ragland emphasizes two-way power more than self-determination and thinks that, according to Descartes, "freedom is most fundamentally the ability to do right" (130, emphasis in original). Evaluation of the relative merits of the the differences in emphasis and interpretation is nonetheless outside the scope of this paper. Importantly, though, it's matter of controversy whether possessing a power, or general ability, is to be analysed or explained in counterfactual terms (for an overview, see Maier 2014, Section 3), as illustrated by the debate over dispositions and the so-called "conditional fallacy" (for classic discussion, see Shope 1978; for critical discussion, see Bonevac, Dever, and Sosa 2006). Even if the possession of a power entails the truth of certain counterfactuals, then, it doesn't follow that the former is to be analyzed or explained in terms of the latter. One advantage of my interpretation is that I needn't take sides on this debate. 
To sum up the discussion so far: by rejecting the specific (but not general) categorical ability to do otherwise as a genuine requirement of Cartesian freedom, we're able to defuse the Anti-Enlightened Freedom Argument as well as make sense of Descartes's reply to Gassendi. In doing so we are also able to avoid appealing to the problematic 'two senses' passage from the 1645 note. (I'll return to it below.) The above interpretation therefore offers a more principled explanation of how Descartes manages to happily affirm the Enlightened Freedom Thesis alongside the rest of the candidate commitments in \$III.A.

This is progress. But of course there's more to be said, both in fleshing out Descartes's overall conception of freedom and in defending the interpretation of the Two-Way Ability Thesis, understood as $\mathrm{TWA}_{\mathrm{G}}$ rather than TWAs. I'll begin with the former task, before concluding with the latter one.

\section{B. Descartes on Self-Determination and the Divine Will}

Recall the potential ambiguity introduced by the two clauses flanking 'or rather' in the main Fourth Meditation passage considered at the outset. Like many others, I take the force of the 'or rather' to be akin to 'in other (better) words'. Descartes, after all, is quite explicit that he is attempting to characterize the will in the "essential and strict sense", and this is the only place he does so. We should therefore take what he says seriously-and what he says is that the will essentially involves the (general) ability to do or not to do and that it involves acting free of external determination. It's plausible, then, to take the two clauses as distinct but related attempts to characterize the essence of the (essentially free) will.

So far, my focus has been on the first clause. But the second clause concerning selfdetermination is just as important, if not more so. Indeed, contrary to what's suggested by the initial gloss provided in the Fourth Meditation, Descartes doesn't equate self-determination with the mere absence of external compulsion-where 'external' plausibly means 'external to the mind (or soul)'-but rather with a "positive power" to determine oneself. This is evident from his 1644 letter to Mesland:

As for animals that lack reason it is obvious that they are not free, since they do not have this positive power to determine themselves; what they have is a pure negation, namely the power of not being forced or constrained. (CSMK, 234; italics added)

According to Descartes, animals that lack reason also lack freedom, even though they are not "forced or constrained". ${ }^{39}$ So clearly the absence of (presumably external) compulsion is insufficient for freedom, even though it is necessary. What makes us different is that we have a 'positive power' to determine ourselves, while they don't.

On Descartes's picture, it is crucially important that we-our selves-are the ultimate causal origin or source of our choices and judgments, and thus "in a special way the author

${ }^{39}$ I don't intend to take a stand on whether physical determinism is true with respect to automatons; lack of external compulsion may well be compatible with physical determinism, on Descartes's view. Thanks to an anonymous referee for prompting this clarification. 
of [our] actions" (CSM I, 205). ${ }^{40}$ For even when the intellect compels the will's assent in cases of CD-perception, it is still the intrinsic properties and powers of our intellect and our will that work in concert; nothing external to the mind impels us. Throughout his corpus Descartes remains steadfast in his allegiance to the thesis that we are free whenever we enjoy CD-perception, even though our will is determined by the intellect in such circumstances, and an understanding of Descartes's metaphysics of mind helps make clear why CD-determination is not only perfectly compatible with but indeed amounts to self-determination. For $\mathrm{CD}$-perception constitutively involves the making explicit of ideas that are innate within us-ideas that we are all (divinely) endowed with as part of our nature, and that therefore owe nothing to the outside material world (cf. Sleigh, Chappel, Della Rocca 1998, 1212-1214). We are thus self-determined in the fullest sense possible in cases of CD-perception, modulo our general dependence on God. All other cases of perception, by contrast, involve obscure and confused ideas that are derived from or tainted by sense perception, and hence depend (at least in part) on that which is external to us qua thinking substance (soul, mind). In this way, "[t]he independence which we experience and feel in ourselves"an independence that makes "our actions praiseworthy or blameworthy", unlike those of animals-is not threatened by CD-perception (CSMK, 277).

Further insight and support for the above interpretation can be gained by considering the following passage from the Principles:

That there is freedom in our will, and that we have power in many cases to give or withhold our assent at will, is so evident that it must be counted among the first and most common notions that are innate in us... [The] freedom which we experienced within us was nonetheless so great as to enable us to abstain from believing whatever was not quite certain or fully examined. (CSM I, 205-206)

This passage is noteworthy for two main reasons. First, Descartes explicitly distinguishes between the freedom which is 'in' or essential to our will and the (we're assuming, categor$\mathrm{ical}_{\mathrm{R}}$ ) power or ability which we have in many-but not all-cases to give or withhold our assent. The former we can identify as the power of self-determination (or general two-way power), while the latter is most naturally interpreted as specific two-way power, since it's a statement concerning our ability to exercise two-way power in particular circumstances. If the latter were essential to the former, we'd expect it to always accompany the will-but it doesn't (or at least that's what's implicated by 'many' ${ }^{41}$ ), so there's good reason to think that it's not. Instead, we only have specific two-way power with respect to that which is "not quite certain or full examined", and hence only when we are indifferent-understood, per above, as the state of the mind when the will is not impelled one way rather than another by CD-perception, or, equivalently, when we have reasons to assent as well as reasons

\footnotetext{
40 This is of course supposed to be compatible with God's ever-guiding and ever-conserving hand. As noted previously, I'm ignoring complications (and possible tensions) in Descartes's view arising from our dependence on God, and God's absolute control over and perfect knowledge of creation.

${ }^{41}$ This is what's known as a "quantity" implicature-saying (e.g.) that you ate some of the cookies implicates that you didn't eat all of them.
} 
not to assent, however unequal they may be (cf. Kenny 1972; Ragland 2006a, 2016; Lennon 2013; Dicker 2013). This makes plausible the following:

9. Necessity Thesis: $S$ has the specific ability to do other than $\varphi$ only if $S$ is indifferent with respect to $\varphi$.

Indifference is thus an "opportunity condition" for two-way power-i.e. a condition that must be satisfied in order for an agent to be able to exercise that power.

Second, Descartes says that our freedom is 'so great' that it enables us to abstain whenever we are indifferent. This suggests that the power of self-determination together with indifference is sufficient for specific two-way power:

10. Sufficiency Thesis: If $S$ has the power of self-determination and $S$ is indifferent with respect to $\varphi$, then $S$ has the specific ability to do otherwise than $\varphi$.

Of course, Descartes thinks our default state as fallen human beings is one that is rife with indifference, with the vast majority of ordinary perceptions being obscure or confused to varying degrees. It therefore follows from the Sufficiency Thesis that our default state is one in which we nearly always have specific two-way power. Such power is thus part and parcel of our normal state of indifference, and a direct consequence of our nature as self-determining agents. So although as a matter of fact we're able to exercise (categorical ${ }_{R}$ ) two-way power with respect to the vast majority of choices and/or judgments we make, this "specific" ability is ultimately just a circumstantial manifestation of the core power constitutive of freedomi.e. the abiding power of self-determination. ${ }^{42}$

42 It's worth noting that the view I'm offering shares important similarities with the view expounded by Kenny (1972), who argues that Descartes "thinks that freewill often does consist in liberty of indifference [understood as a two-way power], but that sometimes it consists only in liberty of spontaneity, and that is all that is essential to it" (18). However, instead of characterizing spontaneity as the positive power of self-determination (as I have), Kenny characterizes it in terms of wanting: "we [enjoy liberty of spontaneity] in doing something if and only if we do it because we want to do it" (17). More importantly, Kenny's distinction between the two kinds of liberty is sharp in a way that mine is not: on my view, the positive power of self-determination manifests itself as specific two-way power in cases of indifference. It's at best misleading to think of the agent as enjoying distinct kinds of freedom or liberty, depending on the circumstances; instead, it is one and the same underlying power to act that is operative in all circumstances. Indeed, for Kenny, the two kinds of liberty come apart in both directions-the liberty of spontaneity, but not the liberty of indifference, is had in cases of CD-perception, and the liberty of indifference, but not the liberty of spontaneity, is had in cases of "full indifference"-i.e. when one "sees no reason to one side rather than another" (30). I resist such dualism. Another notable difference is that Kenny thinks that Descartes's theory is incoherent (and, indeed, consistently so- "it is an incoherence which was present in the theory from the beginning"), while I do not (31). Kenny is misled by Descartes's admittedly confusing — but not confused (see below)—remarks about the "degrees" of freedom; according to Kenny, Descartes falls into incoherence by thinking that there is a "single scale of freedom" while also thinking that there are different kinds of freedom, and which resist linear ordering. But on my view, Descartes thinks neither. For a thorough response to Kenny's worries, and an explanation of where he goes wrong, see Ragland (2006b, 2013, 2016). 
This interpretation helps shed additional light on the 'or rather' passage in the Fourth Meditation, which (as noted in \$III.A) is intended to explain the sense(s) in which the essence of our will is akin to that of God's. For when Descartes writes that the will "simply consists in our ability to do or not do something", he is not talking about the specific ability to do or not do something, but instead the general ability. That this interpretation is correct is strongly suggested by Descartes's remarks immediately following the 'or rather' passage, in which he explicitly (a) denies that indifference is necessary for human freedom, (b) affirms CD-Determination, and (c) affirms the compatibility of CD-perception and human freedom (CSM II, 40-41). These commitments entail that the will is not always, and of necessity, in a position to exercise two-way power. It seems exceedingly unlikely, however, that Descartes would have been guilty of so blatant a contradiction, and so there's excellent reason to take the first clause to merely attribute the essential possession of two-way power to the will, rather than the ability to always exercise such a power. ${ }^{43}$

Like God, then, we essentially possess two-way power, but unlike God, we're not always in a position to exercise that power. This difference is not due to a difference in the nature of the will itself, however. Instead, it's due instead to a difference in our motivational profiles: whereas we (as humans) are merely contingently indifferent, God is essentially indifferent. So although the Necessity Thesis and the Sufficiency Thesis apply to both us and God-we're both only able to exercise two-way power in cases of indifference-God is unique in always, and of necessity, being in a position to exercise that power.

This contrast between us and God is remarked upon in the Sixth Replies:

As for the freedom of the will, the way in which it exists in God is quite different from the way in which it exists in us. It is self-contradictory to suppose that the will of God was not indifferent from eternity with respect to everything which has happened or will ever happen; for it is impossible to imagine that anything is thought of in the divine intellect as good or true, or worthy of belief or action or omission, prior to the decision of the divine will to make it so... Thus the supreme indifference to be found in God is the supreme indication of his omnipotence. (CSM II, 291)

Things are different for us:

But as for man, since he finds that the nature of all goodness and truth is already determined by God, and his will cannot tend towards anything anything else, it is evident that he will embrace what is good and true all the more willingly, and hence more freely, in proportion as he sees it more clearly. He is never indifferent except when he does not know which of the two alternatives is the better or truer, or at least when he does not see this clearly enough to rule out any possibility of doubt... [So, unlike divine indifference,] human indifference does not belong to the essence of human freedom. (CSM II, 292)

\footnotetext{
${ }^{43}$ At least we have good reason to think this given the additional assumption (noted from the outset) that 'or rather' means 'in other (better) words' rather than 'or instead' or 'actually, that's not right...'.
} 
Despite this difference with respect to indifference, however, it's still true that both the divine and the human will possess two-way power, and essentially so. They are also both free from external determination-modulo humans' general dependence on (and potential determination by) God-and hence self-determining. So both clauses describe important points of similarity between the divine and human will, and characterize it from complimentary and mutually reinforcing perspectives-just as we'd expect given the context. ${ }^{44,45}$

The question remains why Descartes prefers the second clause to the first. Fortunately, however, the present interpretation provides a ready answer. For as noted above, the ability to exercise two-way power in cases of indifference is ultimately just a circumstantial manifestation of the core power constitutive of freedom-i.e. the abiding power of self-determination. And that's because if the will were determined by the intellect in cases of indifference it would be determined (in part) by obscure and confused ideas derived from or tainted by sense perception, and hence determined (in part) by that which is external to the mind. ${ }^{46}$ One thus has the (general and specific) ability to do otherwise in virtue of being self-determining, rather than vice versa. In this way, self-determination is metaphysically prior to two-way power, despite both being essential to and characteristic of the will (whether human or divine). The second clause therefore clarifies and expands upon the first without replacing it. ${ }^{47}$

The present interpretation also sits nicely with another notable textual datum-the socalled 'great light' passage. In his 1644 letter to Mesland, Descartes writes:

${ }^{44}$ That these are points of similarity rather than properties that are strictly speaking shared by the divine and human wills is important. For in the relevant passage Descartes clearly states that "no essence can belong univocally to both God and his creatures" (CSM II, 292).

${ }^{45}$ Why does Descartes mention two-way power first, rather than self-determination? It's hard to be certain, but there are at least two reasons to think it made strategic sense. To begin with, there's little doubt that the characterization of the will as the ability "to do or not to do" accords well with common sense as well as common experience, and so the reader would be unlikely to demur. But there's also a not insignificant chance that Descartes had in mind his Jesuit readership, who were well-known for being staunch defenders of the will's two-way power-cf. Lennon $(2013,2015)$.

${ }^{46}$ Again, I'm bracketing issues concerning our general dependence on God, etc.

${ }^{47}$ My reading of the 'or rather' passage thus splits the difference between what Ragland (2016) calls the "expansion" and "clarification" readings (see pp. 86, 89-90). Ragland himself defends the latter, arguing that "the second clause is spelling out an implication of the first clause: when we are able to do something or not (first clause), then we are not determined to do it (second clause). On this reading, the second clause enriches Descartes' notion of freedom not by proposing another kind of freedom distinct from two-way power, but by explicating more fully the notion of two-way power itself" (89). On my view, the situation is different, with the first clause being explained (rather than merely clarified) by the second: it is in virtue of being self-determining that we possess the (general as well as specific) ability to do otherwise. So although I agree that Descartes is not proposing "another kind of freedom distinct from two-way power", I do think he is proposing another, more metaphysically fundamental kind of power (self-determination) -one that guarantees but is not identical to two-way power (in any sense). My interpretation of Descartes's overall view nonetheless shares many similarities with that of Ragland's, though (as already noted) a full and careful comparison is beyond the scope of this paper. 
I agree with you when you say that we can suspend our judgement; but I tried to explain in what manner this can be done. For it seems to me certain that a great light in the intellect is followed by a great inclination in the will, so that if we see very clearly that a thing is good for us, it is very difficult-and, on my view, impossible, so long as one continues in the same thought - to stop the course of our desire. But the nature of the soul is such that it hardly attends for more than a moment to a single thing; hence, as soon as our attention turns from the reasons which show us that the thing is good for us, and we merely keep in our memory the thought that it appeared desirable to us, we can call up before our mind some other reason to make us doubt it, and so suspend our judgement, and perhaps even form a contrary judgement. (CSMK, 233; italics added)

As the italicized clause indicates, whenever (and so long as) the 'great light' of the intellect shines forth, we cannot do otherwise than we actually do. That is, we lack specific two-way power so long as the present circumstances-i.e. our total state of mind, including the CDperception-remain as they are. But as soon as the great light is dimmed, or otherwise diminished (as, say, the result of a change in the level or object of our attention, or the introduction of countervailing reasons), then we are able to exercise the will's two-way power and thus revise our judgment or stop the course of our desire.

\section{Descartes and "Degrees" of Freedom}

At this point it's worth noting that there's an evaluative strain in Descartes's discussion of freedom-one that is readily explained by the present interpretation. Two of the clearest attempts to demarcate different freedom-related concepts are to be found, first, in the Fourth Meditation and, second, in Descartes's 1645 note:

[I]t is above all in virtue of the will that I understand myself to bear in some way the image and likeness of God. For although God's will is incomparably greater than mine, both in virtue of the knowledge and power that accompany it and make it more firm and efficacious, and also in virtue of its object, in that it rangers over a greater number of items, nevertheless it does not seem any greater than mine when considered as will in the essential and strict sense. (CSM II, 40; italics added)

[T] he lowest degree of freedom is that by which we determine ourselves to things to which we are indifferent... For a greater freedom consists either in a greater facility in determining oneself or in a greater use of the positive power which we have of following the worse although we see the better. If we follow the course which appears to have the most reasons in its favour, we determine ourselves more easily; but if we follow the opposite, we make more use of that positive power; and thus we can always act more freely in those cases in which we see much more good than evil than in those cases which are called [indifferent]... But freedom considered in the acts of the will at the moment when they are elicited [consists] simply in ease of operation...It was in this sense that I wrote [in the Fourth Meditation] that I moved towards something all the more freely when there were more reason driving me towards it; for it is certain that in that case our will moves itself with greater facility and force." (CSMK, 245-46; italics added). 
Descartes is speaking somewhat loosely here about 'freedom', given that the essence of the will consists in both the (general) ability do otherwise and the positive power of self-determination, and neither of these come in degrees. What these passages demonstrate, however, is an awareness of the need for more subtle distinctions concerning possible states of the will. In particular, although there's only one kind of freedom-the core, basic power of selfdetermination that enables one to do otherwise in cases of indifference-Descartes distinguishes at least three different dimensions along which particular exercises of freedom, or states of the will, can be evaluated. In particular, the above passages suggest we can exercise our freedom...
quality ...with more or less, and better or worse, objects as our guide.
facility ...with greater or lesser ease, or felt exertion.
force ...with a stronger/weaker will (understood as a measure of absolute strength).

These different dimensions help elucidate some of Descartes's remarks that are otherwise puzzling, in addition to those above. For example, it explains part of the key passage from the Fourth Meditation (quoted above) about how divine grace and "natural knowledge" not only fail to diminish freedom, but rather serve to "increase and strengthen" it (better quality objects result in greater facility and force), and how indifference is the "lowest grade of freedom", because it is evidence of a "defect in knowledge or a kind of negation" (lower quality objects, less facility). Note that in each case what's being evaluated is the overall state of the will in relation to the intellect-rather than just the state of the will itself considered on its own.

We're also able to make better sense of the important and oft-repeated claim that we are "at our freest" when a "clear perception [of the good or the true] impels us" (CSM II, 292; cf. CSM II, 40, 106; CSMK, 245, 342), since this is when we face the least motivational resistance and hence are "able to act with most ease"-assent of the will is immediate and effortless. Not so for cases of non-CD-perception, when the will is presented with opposing reasons (though not necessarily with the same strength) and so inevitably faces some motivational resistance, no matter which way it goes. Thus, although acting freely is an all-ornothing affair and talk of one exercise of the will being unqualifiedly "more free" than another doesn't make sense, talk of one exercise of the will being "more free" than another in terms of the former enjoying greater quality, facility, and/or force is perfectly sensible.

Given all of this it becomes clear that even though the will enjoys the same positive power of self-determination in cases of both CD-perception and non-CD-perception (and hence is equally free), it enjoys additional benefits in the former. Indeed, the "highest" form of freedom, or "best" state of the will, is not only compatible with but consists in the will being compelled by clear and distinct perception. By contrast, being in a position to actually exercise categorical two-way power is a sign of intellectual imperfection-we're only in such a position when we fail to clearly and distinctly perceive what to do or believe, and hence are indifferent-and it guarantees the presence of at least some motivational resistance.

In sum: on the interpretation I favor, there's only one power or faculty of free will, although the way it is manifested may vary depending on the circumstances. In particular, although the possession of two-way power is essential to the will, it's a power that can only 
be exercised in cases of indifference, whereas the power of self-determination is a power that is always exercised, no matter the circumstances, whenever the will acts. Self-determination thus enjoys a kind of priority in Descartes's thought and system. It is the ultimate locus of freedom, it is the basis of moral responsibility, it enables one to do otherwise in cases of indifference, and it is not only compatible with but also manifested most fullywith maximal quality, facility, and force-in the blessed state of rational enlightenment.

\section{The 'Two Senses' Passage}

I find the above interpretation to be compelling. But some obstacles remain, foremost among which are a handful of texts that seem to suggest a unrestricted commitment to specific two-way power-i.e. to us being able to exercise two-way power with respect to all of our actions. I've already dealt with some, including the 'or rather' passage from the Fourth Meditation. I'll conclude by revisiting the 'two senses' passage from the 1645 note.

To begin with, how are we to understand Descartes's claim that the will has two-way power "not only with respect to those actions to which it is not pushed by any evident reasons on one side rather than on the other, but also with respect to all other actions" (CSMK, 245; italics added)? It helps to recall that in his 1644 letter to Mesland (i.e. the 'great light' passage above) Descartes emphasizes how attention is fleeting, and thus how difficult it is to maintain a clear and distinct perception-something which, for most people, is a rare occurrence and requires focused effort-because as soon as our attention shifts "we can call up before our mind some other reason to make us doubt it, and so suspend our judgement, and perhaps even form a contrary judgement" (CSMK, 233). Yet Descartes also insists that when we "see very clearly that a thing is good for us", it is "impossible [to] stop the course of our desire" so long as "one continues in the same thought" (CSMK, 233).

I think Descartes's remarks in the 'two senses' passage can be understood along similar lines. ${ }^{48} \mathrm{He}$ 's not making the modal claim that the will essentially enjoys specific (categorical $_{\mathrm{R}}$ ) two-way power with respect to all of its actions; rather, he's making the de facto claim that the will in fact has such power with respect to all of its actions. But that's not to say that the will is able to exercise two-way power at each moment, for in cases of CD-perception it can't; rather, it is to say that for each action-including assent to CD-perception-either (i) we are in a position to exercise two-way power at the moment of choice, or (ii) there is a moment just prior at which the will was able to exercise such an ability and as a result do otherwise than it in fact did, or (iii) there is a moment just after at which the will can exercise such an ability, and hence do something different. After all, CD-perception isn't usually forced on us, but rather requires a certain amount of effort to achieve. Our default state is one of indifference, with the mind clouded by obscure and confused ideas. And even when CD-perception does come easily, we usually retain control over our attentive gaze, and so can easily turn aside and consider something else, thereby preventing our assent from being (or continuing to be) compelled. ${ }^{49}$

${ }^{48}$ Kenny (1972) also pursues the strategy of interpreting the 'two senses' passage (CSMK, 245) in terms of the 'great light' passage (CSMK, 233). (Thanks to an anonymous referee for pointing this out.)

${ }^{49}$ Ragland (2016) makes similar remarks—see especially Chapter 5. 
We can therefore distinguish two kinds of specific two-way control: direct and indirect. (The 'categorical ${ }_{R}$ ' qualifier will remain implicit.) One has direct two-way control over an action whenever one is in a position to exercise two-way power at the moment of choice. In contrast, one has indirect two-way control when there is a relevant time either prior or posterior to the moment of choice at which the will is able to exercise such an ability and as a result do something other than what is done at the moment of choice. The proposed interpretation thus amounts to this: for any particular action $A$, we always-as a matter of facthave direct or indirect two-way control over $A$. But although this is true of us, it's not necessarily true of us-things would be different in cases of continuous CD-perception, or perfect enlightenment. ${ }^{50}$ The kind of specific control we (i.e. humans) actually-though not necessarily-enjoy with respect to all of our actions can thus be understood as incorporating a backwards-looking "tracing" condition as well as a forward-looking "re-direction" condition: ${ }^{51}$

Two-Way Control: $S$ has two-way control over the performance of an action $A$ at time $t$ if and only if either (i) $S$ is able to do otherwise than $A$ at $t$, or (ii) $S$ was able to perform some other action $B$ at some relevant time $t^{\prime}$ prior to $t$ such that had $S B$-ed at $t^{\prime}$, $S$ would have done (or would have been able to do) otherwise than $A$ at $t$, or (iii) $S$ will be able to do otherwise than $A$ at some relevant time $t$ " posterior to $t$.

Two-Way Control captures the sense in which "it is [de facto!] always open to us [as fallen, unenlightened humans] to hold back from pursuing a clearly known good, or from admitting a clearly perceived truth" (CSMK, 245). The subsequent proviso is simply an example of how we might be motivated to do so-we might divert our attention and thereby hold back because we consider it "a good thing to demonstrate the freedom of our will by doing so" (CSMK, 245).

So even though we lack direct two-way control in cases of CD-perception, and hence "morally speaking" can't do otherwise, we nonetheless as a matter of fact (though not of necessity) retain indirect control over them, and hence "absolutely speaking" we can do otherwise. The present interpretation thus manages to make good sense of the moral-absolute distinction without treating it as the key to understanding Descartes's theory of free

\footnotetext{
${ }^{50}$ Similar remarks apply to the 'automatons' passage considered earlier. It's true that whenever we "embrace the truth, our doing so voluntarily is much more to our credit than would be the case if we could not do otherwise" (CSM I, 205), because our lacking the ability to do otherwise in such circumstances would amount to our lacking direct or indirect two-way control. And that would mean we weren't free, given that we do (de facto!) have such control over our actions. And that would mean we weren't morally responsible, and hence not deserving of credit. (This differs from Ragland's (2016) interpretationsee pp. 123-124.)

${ }^{51}$ Ragland (2006a) likewise appeals to a tracing condition in defending an interpretation of Descartes as a "moderate libertarian" (which is different from the "limited libertarian" interpretation defended in his 2016). I'm appealing to a similar condition but in the service of a different view.
} 
will, as Campbell (1999) does, and without taking it to mark the distinction needed to respond to the Anti-Enlightened Freedom Argument, as Ragland (2016) does. ${ }^{52}$

\section{Conclusion}

As remarked at the outset, several seemingly divergent strains of thought are present in Descartes's writings on freedom, with reactions ranging from allegations of incoherence to inconsistency to change over time. Although I haven't directly rebutted any of the specific charges, I think the interpretation I've offered-one that draws from all of Descartes's major writings as well as his letters, and on which Descartes's view is plausibly coherent, consistent, and stable-suffice for optimism on this score. In addition, it fairs better than the other interpretations I've briefly considered - by Campbell (1999) and Ragland (2016) — in not only providing a straightforward and plausible resolution of the puzzle presented by the Anti-Enlightened Freedom Argument but also providing a straightforward and plausible interpretation of the key texts that motivate it. What's more, I've done so by appealing to an independently motivated and intuitively plausible distinction between possessing a power, exercising a power, and being in a position to exercise it-one that is latent in much ordinary thought and talk about powers and abilities, and so almost certainly one that would have been employed by Descartes as well.

\footnotetext{
${ }^{52}$ Ragland considers three ways of understanding the will's "absolute" two-way power with respect to all its acts:

According to the first way, our possession of such power implies that all of our volitions are undetermined [at least by the intellect]. According to the second, it implies that some are undetermined. But on the third way, it does not imply that any volutions are ever undetermined. (130) Ragland defends the third interpretation, whereas I endorse the second.
} 


\section{References}

Alanen, Lili. 2002. "Descartes on the Will and the Power to do Otherwise." In Emotions and Choice from Boethius to Descartes, edited by Henrik Lagerlund and Mikko Yrjönsuuri, 279-298. Dordrecht: Kluwer Academic Publishers.

Beyssade, Michelle. 1994. "Descartes's Doctrine of Freedom: Differences between the French and Latin Texts of the Fourth Meditations." In Reason, Will, and Sensation: Studies in Descartes's Metaphysics, edited by John Cottingham. Oxford: Clarendon Press.

Bonevac, Daniel, Josh Dever, and David Sosa. 2006. "The Conditional Fallacy." The Philosophical Review 115: 273-316.

Campbell, Joseph Keim. 1999. "Descartes on Spontaneity, Indifference, and Alternatives." In New Essays on the Rationalists, edited by Rocco J. Gennaro and Charles Huenemann, 179-199. New York: Oxford University Press.

Chappell, Vere. 1994. "Descartes's Compatibilism." In Reason, Will, and Sensation: Studies in Descartes's Metphysics, edited by John Cottingham, 177-190. Oxford: Oxford University Press.

Clarke, Randolph. 2009. "Dispositions, Abilities to Act, and Free Will: The New Dispositionalism." Mind 118: 323-351.

Clarke, Randolph. 2015. "Abilities to Act." Philosophy Compass 10 (12): 893-904.

Cottingham, John. 1993. A Descartes Dictionary. Wiley-Blackwell.

Cunning, David. 2007. "Semel in Vita: Descartes" Stoic View on the Place of Philosophy in Human Life". Faith and Philosophy 24: 165-184.

Cunning, David. 2010. Argument and Persuasion in Descartes' Meditations. Oxford: Oxford University Press.

Cunning, David. 2014a. "Descartes' Modal Metaphysics." In The Stanford Encyclopedia of Philosophy (Fall 2014 Edition), edited by Edward Zalta. URL $=<$ https://plato.stanford.edu/archives/ spr2014/entries/descartes-modal/>.

Cunning, David. 2014b. "The First Meditation: Divine Omnipotence, Necessary Truths, and the
Possibility of Radical Deception." In The Cam bridge Companion to Descartes's Meditations, edited by David Cunning, 68-87. Cambridge University Press.

Descartes, René. 1984-1985. The Philosophical Writings of Descartes, Volumes I and II, translated by John Cottingham, Robert Stoothoff, and Dugald Murdoch (CSM). Cambridge: Cambridge University Press.

Descartes, René. 1991. The Philosophical Writings of Descartes, Volume III: The Correspondence, translated by John Cottingham, Robert Stoothoff, Dugald Murdoch, and Anthony Kenny (CSMK). Cambridge: Cambridge University Press.

Dicker, Georges. 2013. Descartes: An Analytical and Historical Introduction, Second Edition. New York: Oxford University Press.

Embry, Brian. 2016. "Descartes on Free Will and Moral Possibility." Philosophy and Phenomenological Research.

Frankfurt, Harry. 1969. "Alternate Possibilities and Moral Responsibility." Journal of Philosophy 66: 829-839.

Fischer, John Martin. 1999. "Recent Work on Moral Responsibility." Ethics 110: 93-139.

Fischer, John Martin and Mark Ravizza. 1998. Responsibility and Control: An Essay on Moral Responsibility. Cambridge: Cambridge University Press.

Franklin, Christopher Evan. 2011a. "The Problem of Enhanced Control." Australasian Journal of Philosophy 89: 687-706.

Franklin, Christopher Evan. 2011b. "Masks, Abilities, and Opportunities: Why the New Dispositionalism Cannot Succeed." The Modern School man 88 (1-2): 89-103.

Franklin, Christopher Evan. 2015. "Everyone thinks that an ability to do otherwise is necessary for free will and moral responsibility." Philosophical Studies 172: 2091-2107.

Gilbert, Christopher. (2005) 'Grades of Freedom: Augustine and Descartes'. Pacific Philosophical Quarterly 86, 201-224. 
Gilson, Etienne. 1913. La libert e chez Descartes et la th eologie. Paris: VRIN.

Greenberg, Sean. MS. "Descartes on Human Freedom and the Will: The Meditations as Conative Exercises."

van Inwagen, Peter. 1983. An Essay on Free Will. Oxford University Press.

Jayasekera, Marie. 2016. "Responsibility in Descartes's Theory of Judgment." Ergo 3 (12): 321-347.

Kenny, Anthony. 1972. "Descartes on the Will." In Cartesian Studies, edited by R. J. Butler, 1-31. Oxford: Basil Blackwell.

Kenny, Anthony. 1975. Will, Freedom, and Power. New York: Barnes \& Noble Books

Kratzer, Angelika. 2012. Modals and Conditionals. Oxford University Press.

Lennon, Thomas M. 2013. “Descartes's Supposed Libertarianism: Letter to Mesland or Memorandum Concerning Petau?" Journal of the History of Philosophy 51 (2): 222-248.

Lennon, Thomas M. 2015. "No, Descartes Is Not a Libertarian." In Oxford Studies in Early Modern Philosophy, Volume VII, edited by Daniel Garber and Donald Rutherford. Oxford University Press.

Maier, John. 2014. "Abilities." In The Stanford Encyclopedia of Philosophy (Fall 2014 Edition), edited by Edward Zalta. URL = <http://plato.stanford.edu/archives/fall2014/entries/abilities/>.

Maier, John. 2015. “The Agentive Modalities." Philosophy and Phenomenological Research 90 (1): 113134.

Mele, Al. 2003. "Agents' Abilities." Noûs 37: 447470.

Nelson, Alan and David Cunning. 1999. "Cognition and Modality in Descartes." Acta Philosophica Fennica: 137-153.

Newman, Lex. 2015. "Attention, Voluntarism, and Liberty in Descartes's Account of Judgment." Res Philosophica 92 (1): 61-91.

Ragland, C. P. 2005. "Descartes on Divine Providence and Human Freedom.” Archiv für Geschichte der Philosophie 87 (2):159-188.
Ragland, C. P. 2006. “Is Descartes a Libertarian?” In Oxford Studies in Early Modern Philosophy, Vol. 3, edited by Daniel Garber and Steven Nadler (eds.), 57-89. Oxford: Oxford University Press.

Ragland, C. P. 2006a. "Descartes on the Principle of Alternative Possibilities." Journal of the History of Philosophy 44 (3): 377-94.

Ragland, C. P. 2006c. "Alternative Possibilities in Descartes's Fourth Meditation." British Journal for the History of Philosophy 14(3): 379-400.

Ragland, C. P. 2013. "Descartes on Degrees of Freedom: A Close Look at a Key Text." Essays in Philosophy 14 (2): 239-268.

Schmaltz, Tad M. 2008. Descartes on Causation. Oxford: Oxford University Press.

Shope, Robert K. 1978. "The Conditional Fallacy in Contemporary Philosophy." The Journal of Philosophy 75: 397-413.

Sleigh, Robert, Vere Chappell, and Michael Della Rocca. 1998. "Determinism and Human Freedom." In Cambridge History of Seventeenth-Century Philosophy, Volume 2, edited by Daniel Garber and M. Ayers, 1195-1278. Cambridge: Cambridge University Press.

Vihvelin, Kadri. 2013. Causes, Laws, and Free Will: Why Determinism Doesn't Matter. New York: Oxford University Press.

Vitz, Rico. 2010. "Descartes and the Question of Direct Doxastic Voluntarism." Journal of Philosophical Research 35: 107-121.

Wee, Cecilia. 2006. "Descartes and Leibniz on $\mathrm{Hu}$ man Free-Will and the Ability to Do Otherwise." Canadian Journal of Philosophy 36 (3): 387-414.

Wee, Cecilia. 2014. "The Fourth Meditation: Descartes and Libertarian Freedom." In The Cambridge Companion to Descartes's Meditations, edited by David Cunning, 186-204. Cambridge: Cambridge University Press. 